\title{
Integrating Biomarkers into Research with Latino Immigrants in the United States
}

\author{
Heather H. McClure ${ }^{1,2}$, J. Josh Snodgrass ${ }^{2}$, Charles R. Martinez Jr. ${ }^{1}$, J. Mark Eddy ${ }^{3}$, \\ Thomas W. McDade ${ }^{4}$, Melanie J. Hyers ${ }^{5}$, Anne Johnstone-Díaz ${ }^{6}$ \\ ${ }^{1}$ Center for Equity Promotion, College of Education, University of Oregon, Eugene, USA \\ ${ }^{2}$ Department of Anthropology, University of Oregon, Eugene, USA \\ ${ }^{3}$ School of Social Work, University of Washington, Seattle, USA \\ ${ }^{4}$ Department of Anthropology and Institute for Policy Research, Northwestern University, \\ Evanston, USA \\ ${ }^{5}$ Department of Romance Languages, University of Oregon, Eugene, USA \\ ${ }^{6}$ Family Resource Center, Bethel School District, Eugene, USA \\ Email: hmcclure@uoregon.edu
}

Received February $5^{\text {th }}, 2013$; revised March $5^{\text {th }}, 2013$; accepted March $15^{\text {th }}, 2013$

Copyright (C) 2013 Heather H. McClure et al. This is an open access article distributed under the Creative Commons Attribution License, which permits unrestricted use, distribution, and reproduction in any medium, provided the original work is properly cited.

\begin{abstract}
Despite extensive research into the toll of persistent psychosocial stress on individual physiology and health, little is known about the effects of chronic biosocial stress for immigrant populations. In the present paper, the authors review challenges encountered when integrating minimally-invasive stress-related biomarkers (e.g., blood pressure, Epstein-Barr Virus [EBV] antibodies, C-reactive protein [CRP], and salivary cortisol), as well as anthropometric (e.g., height, weight, waist circumference) and metabolic measures (e.g., glucose, cholesterol), into research with Latino immigrant adults and families in Oregon, USA. Finally, the authors present lessons learned and discuss strategies to support the full engagement of Latino immigrants as participants in studies that rely on the collection of biological data as a central component of research into psychosocial stress and its effects.
\end{abstract}

Keywords: Biomarker; Latino; Immigrant; Psychosocial Stress

\section{Introduction}

Despite the size of the Latino population in the United States (16.7\% of the US population [US Census Bureau, 2011]), the role of stress as a contributor to poor mental and physical health outcomes among Latinos is little known. This is especially true for the approximately $40 \%$ of Latinos in the United States who are foreign born (Lopez \& Taylor, 2010), and the over 50\% of Latino families in which children are US born of immigrant parents (The Urban Institute, 2010).

Many immigrant families, particularly if recently arrived to the US, experience stressors (i.e., exposure to circumstances) that can contribute to profound psychosocial stress (i.e., the extent to which an individual is challenged to maintain function [McEwen, 2000]). Common stressors for immigrant families include low socioeconomic status (SES), challenges of adapting to life in the U.S. (acculturation), employment uncertainty, discrimination, and concerns about legal status, among others (Rumbaut \& Portes, 2001; Vega \& Kolody, 1985; Vega et al., 2004). In states with unprecedented recent population growth of immigrants, such as Oregon and North Carolina, there may be few formal buffers (e.g., well-established ethnic enclaves, culturally-competent services) against such stressors (Capps et al., 2002; Smokowski \& Bacallao, 2007). Though extensive research has been conducted on the toll of persistent psychosocial stress on individual physiology and health (e.g., Kiecolt-Glaser et al., 1994; McDade et al., 2007), little is known about the effects of chronic biosocial stress for Latino immigrants.

Research with US born populations suggests that chronic psychosocial stress is a key link between challenging social contexts and negative health outcomes (Dressler et al., 2005; William et al., 2003). The measurement of stress among immigrant populations, however, may present unique challenges. As the notion of "stress" is deeply culturally-bound, dominant notions regarding "stress" in the US may be distinct from and even unrecognizable to immigrants, especially if they are recently arrived. Attempts to measure self-reported Latino immigrant stress and its effects using standardized instruments, which are often validated through studies with second and third generation Latinos in the US, may fail to resonate with immigrant respondents. More sensitive and objective measures of stress are needed for a clearer understanding of links between contexts favoring stress and health outcomes among Latino immigrants (Martinez, 2006).

To begin to fill these knowledge gaps, in 2007, the Latino Research Team (LRT) at the Oregon Social Learning Center (OSLC) initiated two pilot research projects to determine the feasibility of collecting biological data among Latino immigrants, and to better "map" the pathways through which psychosocial stressors related to acculturation, discrimination, and SES, among others, influence self-report and biological measures of immigrant stress. Both projects utilized minimally- 
invasive techniques (i.e., saliva collection and pricking a participant's finger with a lancet for the collection of a few drops of blood on filter paper cards). Our use of multiple, complementary biological markers of stress is novel, as most investigations into stress and health have relied upon measures of self-reported stress, rather than upon physiological measures such as stress biomarkers (McDade et al., 2007); this is particularly true for studies involving immigrant populations.

In the present paper, we review challenges encountered when integrating stress-related biomarkers (e.g., blood pressure, Epstein-Barr Virus [EBV] antibodies, C-reactive protein [CRP], and cortisol), as well as anthropometric (e.g., height, weight, waist circumference) and metabolic measures (e.g., glucose, cholesterol), into research with Latino immigrant adults and families in Oregon. Finally, we present lessons learned and discuss strategies to support the full engagement of Latino immigrants in studies that rely on the collection of biological data as a component of research into psychosocial stress and its effects.

\section{Overview of Pilot Studies}

Despite the apparent value of incorporating stress biomarkers into research with Latino immigrants in the US, few previous studies had done so and many questions regarding feasibility remain (Ryan et al., 2006; Steffen et al., 2006). To examine questions relating to participants' comfort with biomarker methods, in 2007, we began a two-phase Latino stress and health study (a.k.a. "The Farmworker Study" or TFS) in collaboration with a highly respected farmworker housing and social service organization, and with biological anthropologists at the University of Oregon and Northwestern University. This cross-sectional study took place in three geographically distant housing complexes in Oregon's northern Willamette Valley; analyses involved 132 Latino immigrant adults ( $\geq 18$ years of age; 86 females, 46 males; 96\% Mexican origin; 96\% were parents). Approximately $38 \%$ of men and $33 \%$ of women had a third grade education or less, with $11 \%$ of men and $19 \%$ of women completing high school or receiving post-secondary education. Ninety-three percent of men and $46 \%$ of women were employed. Heads of household reported an annual median household income of $\$ 15,825$ to support an average household of five people $(S D=1.5)$.

This project was followed by the 2009-2010 Stress and Acculturation Project (SAP), which focused on links among stress, health, and parenting in 44 Latina immigrant mothers and their young children in the $1^{\text {st }}$ to $3^{\text {rd }}$ grades (93\% Mexican origin), and collaboration with the University of Oregon. About a third of mothers (32\%) had a third grade education or less, and $23 \%$ completed high school or received post-secondary education. Forty-three percent of mothers worked outside the home. Mothers reported an annual median household income of $\$ 18,750$ to support an average household of five people $(S D=1.5)$.

\section{Recruitment for Studies}

Study samples were drawn from non-probability designs and recruitment was conducted through trusted social networks, and by recruiters who share characteristics of the target study population (Martinez et al., 2012; Villarruel et al., 2006). TFS took place during the busiest time of year for agricultural workers. Despite this, recruitment was completed quickly with staff of our partner organization recruiting all participants within 10 days. In the SAP pilot, 24 families in the Eugene/Springfield area were recruited in one week. Our participation rate for both pilot studies was $98 \%$.

\section{The Farmworker Study}

On a single day, residents participated in a health assessment and responded to a 20 minute interview. Senior staff from the LRT and the farmworker organization collaborated on the design of the interview. Due to its brevity, specific questions were drawn from a larger assessment battery that had been extensively developed by the LRT for use with the Latino population in Oregon (see Martinez \& Eddy, 2005; Martinez et al., 2009). A focus group composed of Latino immigrant farmworkers reviewed the questionnaire, and changes were made per focus group findings. The SAP interview was modeled after that for TFS, with items added relating to depression and parenting. The Institutional Review Boards at OSLC and the University of Oregon approved all research protocols and all participants provided written consent prior to the assessment. All respondents were assessed in Spanish.

Assessors for TFS included LRT professional interviewers, staff from our partner organization, volunteer undergraduate students, and community members. All assessors received four hours of intensive training in how to conduct the interview and collect biological and health data, and between four and eight hours of on-site supervision. Assessments were scheduled for Saturday and Sunday mornings (residents were given a choice of days), and childcare was provided.

Assessments for the first study were conducted in the community center in each housing complex. The health exam involved measures of blood pressure, height, weight, and waist circumference (WC). Staff used a lancet to prick the participant's finger to collect a drop of blood for the immediate measurement of fasting glucose and total cholesterol (all participants had fasted [ $>8$ hours]), and two drops of blood to dry onto filter paper for later laboratory analyses of EBV antibodies and CRP. Assessors then conducted the interview and provided a one-onone saliva collection demonstration (see cortisol measurement section below for detail). Finally, each participant met with a health educator to review their health values. Participants with measures indicating need for follow-up were referred to partnering public health agencies. During the following week, staff made reminder calls to participants the evening before and the day of each saliva collection. A week after the health assessment, a staff member collected participants' saliva samples and transported them to the laboratory for later analysis. Participants received $\$ 30$ in compensation. Findings from this study have been reported elsewhere (McClure et al., 2010a, 2010b, 2010c, 2012; Midttveit et al., 2010; Squires et al., 2012).

\section{The Stress \& Acculturation Project}

The SAP study incorporated similar indicators and involved only LRT assessors. This study was conducted in the homes of participating families and involved two visits approximately one week apart. At the first home visit, data were collected on mother and children's height, weight, WC, and blood pressure. Staff also conducted a $30-40$ minute interview with mothers and provided training in the collection of saliva samples. Though we measured blood pressure for both mothers and children, our focus was on mothers' blood pressure; we measured children's blood pressure as part of the health information 
provided to families as an incentive for participation. Mothers received $\$ 15$ at the completion of the first home visit, and children were given a toy of their choice.

The second home visit occurred upon completion of saliva collection. A few drops of blood generated through finger stick were analyzed for separate measures for mother and child. Mothers' fingers were pricked first and analyzed for fasting glucose and lipid levels (i.e., total cholesterol, HDL cholesterol, triglycerides, and calculated LDL cholesterol; equipment information below). The assessor then pricked the child's finger to test for hemoglobin levels (a test for anemia; equipment information below). Mothers were given a copy of their own and their child's health values, health information in Spanish, and a list of local clinics for follow-up if indicated. An exit interview ( 5 minutes) was administered to the mother regarding her and her child's experience in the project. Assessors also picked up saliva samples and delivered them to a lab for later analysis. For compensation, mothers received $\$ 15$ and children chose a toy.

\section{Measurement of Psychosocial Stress}

Our investigation of physiological measures of psychosocial stress is informed by a large body of research dating back to Selye (1956), and integrates complementary biomarkers to better understand how stress gets "under the skin" to affect health (McDade, 2007). The following briefly reviews the specific biomarkers and health measures used in TFS and SAP and measurement techniques.

\section{Cortisol}

The hypothalamic-pituitary-adrenal (HPA) axis has been recognized for its important role in the stress response and, in particular, its role in energy mobilization (Sapolsky et al., 2000). Cortisol, the primary glucocorticoid hormone in humans and a marker of HPA activity, has a strong diurnal rhythm with highest levels typically occurring in the early morning hours and lowest levels in the late evening (Kirschbaum \& Hellhammer, 2000). Over time, everyday negatively perceived experiences can contribute to atypical cortisol fluctuation with either high or blunted cortisol levels in the morning, and flatter diurnal curves over the day. Although increased cortisol release in response to acute stressors can be adaptive, the prolonged activation of the HPA axis can lead to HPA dysregulation with downstream effects including the progression of various diseases, such as obesity, type 2 diabetes, and cardiovascular disease (McEwen \& Wingfield, 2003). Studies indicate that Latinos have significantly flatter diurnal cortisol slopes than Caucasians due perhaps to greater stress exposure, including perceived discrimination (DeSantis et al., 2007).

Measurement. In TFS, cortisol was measured from six saliva samples: each participant collected three samples each day for two consecutive days. The SAP study involved nine samples per participant with mothers collecting their own and their child's saliva three times a day for three consecutive days. Adult participants collected $1.0 \mathrm{~mL}$ of saliva in Eppendorf tubes from themselves (and from any participating child) upon awakening, within 30 minutes of awakening, and a half-hour before bedtime. In addition, adult participants were asked to record the date and time of the collection of each sample. In SAP, mothers were asked to maintain a saliva diary for themselves and their child that recorded the exact time and date of sample collection, substances used in the prior 24 hours that might interfere with cortisol assay (e.g., medications, tobacco, and alcohol), and major events during the day. Participants were instructed not to eat, smoke, brush their teeth, drink alcoholic or caffeinated beverages, or engage in intense physical activity in the $30 \mathrm{~min}$ utes prior to each sample due to possible changes in salivary cortisol concentrations (Pollard \& Ice, 2007). To ensure the stability of salivary cortisol (Kirschbaum \& Hellhammer, 2000), participants were instructed to refrigerate all saliva samples until a staff member collected them during a follow-up visit and transported them in an ice chest to the Snodgrass laboratory. Once in the lab, all samples were stored frozen at $-30^{\circ} \mathrm{C}$ in a secure location until analysis. All cortisol samples were analyzed using enzyme immunoassay with a commercially available salivary cortisol assay kit (Salimetrics, State College, PA).

\section{Epstein-Barr Virus Antibodies}

Over the past two decades, EBV antibody levels have been applied as a useful biomarker of chronic psychosocial stress (McDade, 2007). EBV is a ubiquitous herpes virus for which 80 to 90 percent of adults and adolescents in the US test positive by the age of 40 (Jones \& Straus, 1987), though little is known about EBV prevalence among children. Once infected, individuals harbor the virus for life in infected cells. Adequate cell-mediated immune function maintains the virus in a latent state and most adults infected with EBV are clinically asymptomatic (Henle \& Henle, 1982). Stress-induced immunosuppression, however, allows EBV to reactivate, which may trigger an antibody response (Glaser et al., 1991). Thus, EBV antibodies provide a measure of cell-mediated immune function over the duration of several days or weeks (McDade, 2007). Researchers have found elevations in EBV antibody levels among adults in poor quality marriages (Kiecolt-Glaser et al., 1994), children experiencing family stress (McDade et al., 2000), and Latino men who report discrimination stress (McClure et al., 2010a, 2010b). Because of EBV's utility as a marker of chronic psychosocial stress, it has been incorporated into the National Longitudinal Study of Adolescent Health (Add Health) and the World Health Organization's Study on Global Ageing and Adult Health (SAGE).

Measurement. EBV was measured through the collection of dried blood spot samples. Following standard procedures (McDade et al., 2000), each participant had their finger pricked with a sterile disposable lancet; 2 - 5 drops (approximately 50 $\mu \mathrm{L}$ ) of whole blood were then collected on standardized filter paper (No. 903; Whatman). Blood spot samples were then dried overnight, and stored at $-80^{\circ} \mathrm{C}$ until laboratory analysis. Blood spot EBV antibodies were measured using DiaSorin (Stillwater, MN) EBV VCA IgG kits according to a high-sensitivity enzyme-linked immunosorbent assay (ELISA) protocol described elsewhere (McDade et al., 2000). In our studies, all participants were seropositive for EBV antibodies. Protocols in English and Spanish are available online (http://www.bonesandbehavior.org/dbsprotocol.pdf).

\section{C-Reactive Protein}

CRP is a nonspecific acute phase reactant that rapidly increases in plasma concentration in response to inflammation, infection, and injury (Pepys \& Hirschfeld, 2003). Studies have 
linked minor CRP elevations, previously considered clinically normal, with increased cardiovascular risk (Ridker et al., 1998). Elevated levels of CRP are linked to factors such as obesity (Rexrode et al., 2003), and with several dimensions of psychosocial stress, including lack of social integration (Ford et al., 2006) and low SES (Nazmi \& Victora, 2007). Few studies involving CRP have been conducted with Latino populations (Midttveit et al., 2010).

Measurement. CRP was measured through the collection of dried blood spot samples following the same procedure descrybed above for EBV. CRP samples were used for two purposes. First, CRP was used to identify acute infection or tissue injury, which could potentially impact EBV antibody levels. Second, subclinical CRP concentrations were used as indicators of chronic inflammation, and for the examination of whether lowlevel elevations CRP concentrations related to psychosocial stressors. CRP was analyzed using a high-sensitivity enzyme immunoassay protocol (McDade et al., 2004) that uses BioDesign International (Saco, ME) capture and detection antibodies.

\section{Blood Pressure}

It is well-established that blood pressure is associated with diet and physical activity, among other lifestyle factors. In addition, psychosocial stress related to perceived discrimination and low SES have been shown to correlate with elevated systolic blood pressure (SBP) and diastolic blood pressure (DBP; Dressler et al., 2005). The few studies among Latino adults in the US reveal important gender differences (Steffen et al., 2006), with higher discrimination stress relating to higher SBP among men only (McClure et al., 2010a).

Measurement. For the first pilot study, blood pressure (SBP and DBP) was measured using an Omron HEM-422CRLC manual inflation oscillometric blood pressure monitor (Vernon Hills, IL); for each individual, blood pressure was measured twice, separated by at least 10 minutes. In a few cases involving obese participants, blood pressure was measured with a manual sphygmomanometer by a registered nurse. In the second pilot study, blood pressure was measured using an Omron HEM907XL professional oscillometric instrument (Bannockburn, IL). In both studies, blood pressure was measured by a trained assessor using standard procedures (Chobanian et al., 2003).

\section{Anthropometric and Metabolic Values}

Chronic stressors such as job strain, divorce, and perceived discrimination have been associated with greater levels of fasting glucose, lipids, and insulin (Vitaliano et al., 2002). Findings from the British Whitehall studies indicate that the degree to which individuals were treated unfairly independently predicted larger waist circumference, higher hypertension, triglycerides, and fasting glucose, and lower serum HDL cholesterol, even after controlling for SES, behavioral risk factors, and other psychosocial factors (DeVogli et al., 2007). Extensive evidence also illustrates links between chronic stress and depression, which can lead to increased caloric intake, elevated BMI, and associated metabolic and coronary risks (Dallman et al., 2003).

Chronic stress can trigger a complex cascade of behavioral and physiological changes that contribute to the development of the metabolic syndrome (MetS). MetS is characterized by a constellation of risk factors including abdominal obesity, insu- lin resistance, and elevated blood pressure and plasma lipid levels that ultimately can lead to type 2 diabetes (Sattar et al., 2008) and cardiovascular disease (Byrne \& Wild, 2005). Though there is a burgeoning literature on Latino adult and child obesity, type 2 diabetes, hypertension, and their contributors, few studies have focused on psychosocial stress and Latino metabolic function (McClure et al., 2010b; Weigensberg et al., 2008). In the SAP study, 33\% of mothers had values indicating MetS, comparable to high (and rising) national prevalence rates.

Measurement. In both studies, stature, body mass, and WC were recorded using established procedures (Lohman et al., 1988). Body mass index (BMI) was calculated as mass divided by height in meters squared $\left(\mathrm{kg} / \mathrm{m}^{2}\right)$. In the first study, glucose and total cholesterol concentrations $(\mathrm{mg} / \mathrm{dL})$ were obtained from fasted participants using $30 \mu \mathrm{L}$ samples of capillary blood collected from finger prick and using a CardioChek PA analyzer and PTS Panels (Polymer Technology Systems, Indianapolis, IN). This professional testing system meets standard clinical guidelines for accuracy and precision. In the second study, Cholestech LDX monitors (Hayward, CA) were used for the measurement of fasting glucose and lipid levels from $35 \mu \mathrm{L}$ samples of capillary blood collected from finger prick. Presence of the metabolic syndrome was assessed using the updated ATP III criteria (Grundy et al., 2005).

\section{Hemoglobin}

Chronic childhood anemia can contribute to delays in mental and physical development, and evidence is increasing that Latino toddlers have a high rate of anemia related in part to poverty and acculturation factors (Brotanek et al., 2007). As parents in our first project considered this health information highly valuable, we included it in the SAP study to encourage recruitment and retention.

Measurement. Hemoglobin is considered a standard measure for assessing anemia, and values are interpreted based on ageand sex-specific cutoffs. Children's blood hemoglobin in SAP was measured from a drop of blood obtained from finger stick, and assessed using the HemoCue Hb201+ (Lake Forest, CA) to determine if levels were within normal range (typically over 11 $\mathrm{g} / \mathrm{dL}$ ). This system has been extensively validated and its accuracy is within $\pm 1.5 \%$ of the reference method.

\section{Lessons Learned}

Despite the development of new techniques for the measurement of stress outside of clinical settings, there can be barriers to their incorporation in studies with Latino populations in general and with Latino immigrant groups in particular (National Institutes of Health, 2002). We were interested to learn whether the integration of health measures and biomarkers into our studies reduced historic barriers or instead served as an additional challenge to participation in research. Lessons learned (Table 1) include ways to best support participants' compliance with complex and time-sensitive protocols, especially given long days spent in agricultural work and unpredictable daily routines. Ultimately, our goal is to contribute to knowledge about successful practices for engaging ethnic minorities, including immigrant populations, in research in order to contribute to effective interventions with these populations (National Institutes of Health, 2001). 


\section{H. H. MCCLURE ET AL.}

Table 1.

Summary of lessons learned: challenges, solutions, and future strategies for biomarker research with Latino immigrants.

\begin{tabular}{|c|c|}
\hline Challenge & Solution/Future Strategy \\
\hline $\begin{array}{l}\text { Training staff with no prior experience collecting health and biological } \\
\text { data }\end{array}$ & Ample training time + "hands-on" supervised training \\
\hline Barriers to care $(\mathrm{BtC})$ & $\begin{array}{l}\text { Provision of health information \& follow-up } \\
\text { referrals as indicated }\end{array}$ \\
\hline $\begin{array}{l}\text { BtC: Limited knowledge about pre-existing conditions that could } \\
\text { render ineligible for study }\end{array}$ & Testing (e.g., of glucose) as pre-condition of study enrollment \\
\hline BtC: Potential over-enrollment of sick/health-focused participants & Eligibility criteria and encouragement of healthy enrollees \\
\hline Distrust among prospective participants & Recruiter characteristics + recruitment methods that rely on trusted social networks \\
\hline Lack of familiarity with biological data collection & $\begin{array}{l}\text { Creation of strong rapport to ensure open } \\
\text { communication; assessors offer clear explanations; on-line videos of data } \\
\text { collection techniques to increase participant exposure }\end{array}$ \\
\hline $\begin{array}{l}\text { Measurement of very obese participants' blood pressure with Omron } \\
\text { 422-CRLC }\end{array}$ & $\begin{array}{l}\text { Manual blood pressure readings by trained staff person or use of Omron } \\
\text { HEM-907XL for automatic measure }\end{array}$ \\
\hline Saliva sample return rate & $\begin{array}{l}\text { One-on-one training of participants; reminders; support for participants with low } \\
\text { literacy; } \\
\text { involvement of children }\end{array}$ \\
\hline Busy morning schedules & $\begin{array}{l}\text { Collection of one morning sample; participants advised to collect on days with less } \\
\text { busy morning schedules }\end{array}$ \\
\hline Filling out saliva diaries & $\begin{array}{l}\text { Reminders; fewer questions; support for } \\
\text { participants with low literacy; participants call automated system }\end{array}$ \\
\hline $\begin{array}{l}\text { Conducting finger sticks with farmworker participants with calloused } \\
\text { hands }\end{array}$ & $\begin{array}{l}\text { Use of BD Microtainer Contact-Activated lancets (blue) with a high flow blade } \\
(2.0 \times 1.5 \mathrm{~mm})\end{array}$ \\
\hline Effective follow-up with participants & $\begin{array}{l}\text { Partner with community organization with trained staff and resources for } \\
\text { follow-up; hire or have volunteer trained health professional as part of research } \\
\text { team to conduct follow-up }\end{array}$ \\
\hline
\end{tabular}

\section{Assessor Training}

As previously mentioned, staff members in TFS received four hours of intensive training followed by 4 to 8 hours of onsite supervision to hone their newly acquired skills. Following training, staff from our partner organization that had no prior experience with biological measures was able to consistently and accurately collect health data and biomarker samples. The same training model was implemented with the SAP study with staff measurement techniques remaining consistent across both studies. Though assessors had ample time to gain the necessary skills, assessor confidence was the largest issue in training staff new to biological data collection. Assessors often reported feeling comfortable applying their newly acquired skills only after having completed two or three actual visits with families, which included an experienced staff person to provide guidance if necessary.

\section{Recruitment and Health Information}

The incorporation of biomarkers into our studies did not serve as a disincentive or barrier to participation. On the contrary, participants were eager for information about their health, and for referrals and information about bilingual/bicultural, sliding scale, and immigrant-friendly health services. In exit interviews, participants frequently cited our provision of their health values as a major reason for their study participation. Although financial compensation was appreciated, many families regarded it as an added benefit and some stated it was unnecessary. The value of health information was further reflected in some families' offers to pay to obtain measures for non- participating family members, and in requests that we include additional family members in future studies. In addition to providing participants with immediate information about their levels of fasting glucose, total cholesterol and other lipids, several participants requested their individual cortisol, EBV and CRP measures after laboratory analyses were completed.

The provision of health information to participants raised two critical issues: 1) the need for adequately trained health personnel and a referral system (discussed below), and 2) the potential overrepresentation of sick or health-focused participants in the study, particularly as we did not utilize a random sampling approach. The second concern was addressed to some extent by eligibility criteria stating that prospective participants be healthy, and excluding individuals with colds, the flu, or chronic conditions such as diabetes or autoimmune disorders (e.g., Crohn's disease). Given barriers to access to care that are particularly acute for recent immigrants, a number of prospective participants had no knowledge of whether they had chronic and potentially disqualifying conditions. For instance, some women had been diagnosed with gestational diabetes but had never received follow-up testing and were unaware if they currently had diabetes. In cases involving possible diabetes, assessors conducted a preliminary fasting glucose test as a pre-condition of study enrollment, and individuals with a glucose value indicating diabetes were excluded from participation (and provided with referrals for follow-up). As this circumstance affected approximately $15 \%$ of all potential participants, our studies required additional supplies and assessor time than previously anticipated. Given pervasive barriers to care in the US among Latinos in general and immigrant populations in particular, we 
anticipate researchers nationwide will encounter this challenge.

Finally, to date, we have conducted cross-sectional studies and have yet to confront the prospect that could arise in a longitudinal study of influencing participant behavior and subsequent waves of data through the provision of health information in the first wave of assessment. Because of the risk of influencing participant behavior, some OSLC longitudinal studies that incorporate health data and stress biomarkers have opted not to provide participants with information about their health.

\section{Rapport and Effective Communication}

As in most prevention research, strong rapport between participants and assessors in our studies was key to participants' full engagement. This rapport was especially important for recruittment of some Latino immigrants who wished to remain part of a "hidden" population in response to a hostile social and political climate (Martinez et al., 2012). In addition, rapport led to open communication that facilitated participants' learning about potentially complex procedures (e.g., saliva collection), their timely communication with us when there were problems, and our ability to effectively support participants' involvement.

\section{Familiarity with Methods}

Nearly all participants were familiar with measures of height, weight, and blood pressure, though most were unfamiliar with finger sticks and saliva collection. In addition to providing an overview of methods as part of our informed consent process, assessors took special care while performing all health assessment procedures, including finger sticks, to explain each step and invite questions. During one-on-one saliva collection training, assessors also discussed insights we hoped to gain into stress among Latino immigrants through analysis of salivary cortisol, and the importance of participants' adherence to instructions for the accuracy of results. Finally, in the SAP study, assessors pricked mothers' fingers first, which often helped to reduce any anxiety the child felt. Together, these steps may have contributed to only one SAP mother and three children reporting that finger sticks were challenging, and to high return rates of saliva samples (details below). In the future, our team has considered creating short Spanish language demonstrations that could be accessed via DVD or the Internet to provide families with even more information about and exposure to biological data collection methods.

\section{Blood Pressure: Measurement Challenges}

In TFS, when using Omron manual blood pressure machines (HEM-422CRLC), we had trouble getting blood pressure readings for several morbidly obese participants. Though blood pressure cuffs were appropriately sized for each participant, error messages persisted. This challenge of reading blood pressure among some obese individuals, which has been noted in clinical settings, was worrisome given high rates of obesity within the study population at $30 \%$ for men and $33 \%$ for women, which included approximately $7 \%$ with morbid obesity.

In the second phase of TFS, our staff included a registered nurse who took manual blood pressure readings using a sphygmomanometer. In order to avoid stigmatizing visibly obese participants whose blood pressure we anticipated might be difficult to measure, the nurse worked at station one (where the first of two blood pressure measures was taken) and volunteered to take the participant's blood pressure. As it was common at station one for multiple assessors to measure participants' blood pressure at the same time, this strategy worked well to normalize the nurse's intervention. The nurse then tracked participants throughout the health exam and stepped in to take the second blood pressure reading at the final station to ensure consistency of measurement. In the SAP study, we used Omron HEM907XL professional oscillometric instruments (Bannockburn, IL) for the automatic measure of mothers' and children's blood pressure. Though these devices were significantly more expensive than the Omron 422-CRLC, they proved more reliable and we encountered no measurement difficulties.

\section{Finger Sticks: Lancets}

The choice of lancets was important for ensuring that a single finger prick was sufficient to produce an adequate number of blood drops for the measurement of glucose and lipids (adults), hemoglobin (children), and for blood spot cards. In TFS, we initially used Stat-Let Auto lancets (Stat Medical Devices, Inc.) with a depth of $2.2 \mathrm{~mm}$. These lancets, however, were too shallow to draw sufficient blood as most male and some female participants had thick calluses from agricultural work. The most effective lancets we identified for use with this population are BD Microtainer Contact-Activated lancets (blue) with a high flow blade $(2.0 \times 1.5 \mathrm{~mm})$. We also used BD lancets with mothers and children in the SAP study. However, for very young children, researchers may wish to consider using smaller lancets (e.g., Stat-Let Auto lancets of $2.0 \mathrm{~mm}$ ).

\section{Saliva Collection: Supporting Participant Engagement}

In TFS, $70 \%$ of participants returned all six saliva samples. In the SAP study, $98 \%$ of participants returned all nine saliva samples, considered an excellent return rate (Adam \& Kumari, 2009). We attribute these high return rates to training (discussed above), collection reminders, support for participants with limited literacy and the involvement of children (in SAP).

Reminders. Participants reported that the following methods helped them to remember to collect their saliva according to instructions: 1) toothbrush cover labels and removable stickers for bathroom mirrors reading "Pare! Colecte su muestra" (Stop! Collect your sample); 2) colorful wrist "gel" bands that participants donned the evening before as a reminder to collect their saliva when they woke in the morning; and 3) assessors' reminder calls made the evening before. Additional calls the day of collection served as a further reminder, and provided participants with a chance to ask questions, voice concerns, or request additional supplies.

Literacy. In the first study, we learned that our saliva collection directions were difficult for participants with limited literacy to understand. Though we considered designing an alternative set of instructions composed of diagrams and two or three words in lieu of each step, staff from our partner organization advised that a customized approach would be more useful to participants. Ultimately, when working with participants with low literacy, assessors handwrote instructions on the saliva collection guide tailored for each participant's comprehension level.

Involvement of children. During the SAP study, we learned that children as young as six years of age were often eager and quick to learn saliva collection procedures. As a result, we 
actively involved both mother and child in the training, with children often reinforcing their mother's learning. Though we did not formally ask about children's involvement in saliva collection (e.g., whether they initiated collection, or reminded mothers of the need to collect), participant comments indicated that children were an important factor in the family's full participation in the saliva collection portion of the study.

\section{Saliva Collection: Morning Schedules}

In the SAP study, early morning visits for the collection of fasting measures, which could involve arriving at the family's home as early as 5 am so that the mother could leave for work on time, were disruptive for families. In order to collect two morning samples 30 minutes apart, busy morning schedules led some mothers to alter their own and their youngster's wake up times, potentially influencing morning cortisol levels. For studies incorporating two or more morning measures, assessors may wish to relay to participants the possible need to alter their schedules to allow for extra time (not including an earlier wake-up time or collection on a day that is not a typical weekday) or discuss reducing the number of samples on a given morning.

\section{Saliva Collection: Saliva Diaries}

In TFS, of participants who returned saliva samples, $86 \%$ also filled out and returned a half-page form where they recorded the days and times they collected their saliva. In the SAP study, $95 \%$ of participants recorded the time of day and date they collected each sample. These data are critical because they allow staff to track irregularities in collection schedules, and make possible the calculation of time lapses between samples for the study of cortisol level changes throughout the day. Again, reminder calls by staff seemed to facilitate these high response rates.

Mothers in SAP also were asked to respond to questions in a saliva diary for both themselves (6 - 16 Questions) and their participating child (2 - 8 Questions) every time they collected a saliva sample. Questions ranged from the time and day of saliva collection to inquiries about sleep patterns and emotional state during each 24-hour period, factors known to covary with Salivary cortisol levels. Though most participants responded to items whose range of responses were on a five-point Likert scale, open-ended questions asking for more detail were rarely filled out. Participant feedback to assessors indicated that some participants lacked time to respond to all questions. In addition, some participants reported that the saliva diaries were overwhelming in length. In the future, assessors advised asking fewer questions and having a binder for the saliva diaries where all questions would be color coded to the sample collection tubes for that day and clearly separated by collection time.

Literacy. Saliva diaries in the SAP study presented significant challenges to the participation of a few mothers with low literacy. In these cases, the assessor called the family at each collection time and administered the saliva diary as a telephone interview. Though saliva diary data collected by telephone proved to be more complete than data in saliva diaries that participants filled out themselves, telephone interviews were burdensome schedule-wise for mothers and assessors and less costeffective. In the future, we will investigate new strategies that support the inclusion of participants with low literacy, such as requesting that participants call in and respond to pre-recorded questions through an automated system.

\section{Referral System and Follow-Up}

As mentioned, the receipt of health information was one of the greatest incentives for participants' involvement in the studies. Despite widespread enthusiasm regarding this facet of our studies, however, several issues were raised. Approximately one-third of all TFS and SAP participants had high levels of glucose, total cholesterol or other lipids, and blood pressure indicating the need for follow-up testing. Additional participants were referred for follow-up relating to chronic pain, low blood pressure, impaired vision (needing glasses), smoking, nutriation, the self-administration of medication, and desire to lose weight.

Effective follow-up in TFS was facilitated by a number of factors. All participants were easy to re-contact as they were residents of housing complexes owned and run by the organization, and the organization's staff (many of whom were study assessors) already referred residents to a range of services. Also, a key member of the organization's staff and of our research team was an experienced health promoter who had strong relationships with local public health agencies and community clinics.

The SAP study was distinct in that it was not a communitypartnered project and all follow-up was conducted by LRT assessors. In this study, some participants' busy schedules contributed to assessors feeling rushed to explain the results, which was worrisome to staff when trying to explain values that indicated need for follow-up testing. Further, although assessors clearly explained that they were not medical personnel and could not offer advice, participants frequently asked health related follow-up questions. Finally, a few families requested assessor support in making appointments with clinics. Though staff provided support to every participant who requested it, future studies involving larger sample sizes and more compressed assessment timelines would do well to include funding for a health professional (or have a committed volunteer) to respond to families' questions and concerns, and to serve as a health care navigator by assisting participants to access follow-up care.

\section{Conclusion}

Though recent developments in minimally-invasive biological measurement allow for more refined understandings of the effects of psychosocial stress, these methods have been underutilized in studies with Latino populations. This is unfortunate given existing Latino health disparities and the need to better understand contributors to these disparities. Studies involving recent immigrants, however, can confront unique challenges. There is a clear need to fully support Latino immigrants' involvement in research involving biomarkers - and to identify the strategies that make this possible - in order to better inform public health policy and clinical practice. Further, carefully designed studies can provide potential positive benefits to individuals who take part and to the larger communities in which they are members. Finally, though the studies described here focus on the Latino immigrant community, better models of stress processes that rely on multiple measures may have implications for a range of preventive interventions that target the 
effects of stress on family health within diverse communities.

\section{Acknowledgements}

The authors thank the Oregon Latino families who participated in the studies and study assessors. We also thank Felicia Madimenos for biomarker training assistance, Julia RidgewayDíaz and Sasha Johnson-Freyd for cortisol analyses, and Lynn Stephen and Frances White for discussions of the project. We appreciate the support of the National Institutes on Drug Abuse, National Institutes of Health (R01 DA017937 and R01 DA01965), as well as the Oregon Social Learning Center Scientists' Council, Northwestern University, the University of Oregon (UO), and the UO Center for Latino/a and Latin American Studies (CLLAS).

\section{REFERENCES}

Adam, E. K., \& Kumari, M. (2009). Assessing salivary cortisol in large-scale, epidemiological research. Psychoneuroendocrinology, 34, 1423-1436. doi:10.1016/j.psyneuen.2009.06.011

Brotanek, J. M., Gosz, J., Weitzman, M., \& Flores, G. (2007). Iron deficiency in early childhood in the United States: Risk factors and ethnic/racial disparities. Pediatrics, 120, 568-575.

doi:10.1542/peds.2007-0572

Byrne, C. D., \& Wild, S. H. (2005). Review of the metabolic syndrome. Chichester, West Sussex: John Wiley \& Sons, Ltd. doi:10.1002/0470025131

Capps, R., Fix, M. E., \& Passel, J. S. (2002). The dispersal of immigrants in the 1990s: Policybrief \#2.

http://www.urban.org/publications/410589.html

Chobanian, A. V., Bakris, G. L., Black, H. R., Cushman, W. C., Green, L. A., Izzo Jr., J. L. et al. (2003). Seventh report of the Joint National Committee on prevention, detection, evaluation, and treatment of high blood pressure. Hypertension, 42, 1206-1252. doi:10.1161/01.HYP.0000107251.49515.c2

Dallman, M. F., Pecoraro, N., Akana, S. F., la Fleur, S. E., Gomez, F., Houshyar, H. et al. (2003). Chronic stress and obesity: A new view of "comfort food". Proceedings of the National Academy of Scienes, 20, 11696-11701. doi:10.1073/pnas.1934666100

DeSantis, A., Adam, E., Doane, L., Mineka, S., Zinbarg, R., \& Craske, M. (2007). Racial/ethnic differences in cortisol diurnal rhythms in a community sample of adolescents. Journal of Adolescent Health, 41, 3-13. doi:10.1016/j.jadohealth.2007.03.006

DeVogli, R., Brunner, E., \& Marmot, M. G. (2007). Unfairness and the social gradient of metabolic syndrome in the Whitehall II Study. Journal of Psychosomatic Research, 63, 413-419. doi:10.1016/j.jpsychores.2007.04.006

Dressler, W. W., Oths, K. S., \& Gravlee, C. G. (2005). Race and ethnicity in public health research: Models to explain health disparities. Annual Review of Anthropology, 34, 231-252. doi:10.1146/annurev.anthro.34.081804.120505

Ford, E. S., Loucks, E. B., \& Berkman, L. F. (2006). Social integration and concentrations of C-reactive protein among US adults. Annals of Epidemiology, 16, 78-84. doi:10.1016/j.annepidem.2005.08.005

Glaser, R., Pearson, G. R., Jones, J. F., Hillhouse, J., Kennedy, S., Mao, H. et al. (1991). Stress-induced activation of Epstein-Barr virus. Brain, Behavior, and Immunity, 5, 219-232. doi:10.1016/0889-1591(91)90018-6

Grundy, S. M., Cleeman, J. I., Daniels, S. R., Donato, K. A., Eckel, R. H., Franklin, B. A. et al. (2005). Diagnosis and management of the metabolic syndrome: An American Heart Association/National Heart, Lung, and Blood Institute Scientific Statement. Circulation, 112, 2735-2752. doi:10.1161/CIRCULATIONAHA.105.169404

Henle, W., \& Henle, G. (1982). Epstein-Barr virus and infectious mononucleosis. In R. Glaser, \& T. Gottleib-Stematsky (Eds.), Human herpesvirus infections: Clinical aspects (pp. 151-162). New York: Marcel Dekker.
Jones, J. F., \& Straus, S. E. (1987). Chronic Epstein-Barr virus infection. Annual Review of Medicine, 38, 195-209. hdoi:10.1146/annurev.me.38.020187.001211

Kiecolt-Glaser, J. K., Malarkey, W., Cacioppo, J. T., \& Glaser, R. (1994). Stressful personal relationships: Endocrine and immune function. In R. Glaser \& J. K. Kiecolt-Glaser (Eds.), Handbook of human stress and immunity (pp. 321-339). San Diego, CA: Academic Press.

Kirschbaum, C., \& Hellhammer, D. H. (2000). Salivary cortisol. In G. Fink (Ed.), Encyclopedia of stress (Vol. 3, pp. 379-384). San Diego: CA: Academic Press.

Lohman, T. G., Roche, A. F., \& Martorell, R. (Eds.) (1988). Anthropometric standardization reference manual. Champaign, IL: Human Kinetics Books.

Lopez, M. H., \& Taylor, P. (2010). Latinos and the 2010 census: The foreign born are more positive. http://pewhispanic.org/files/reports/121.pdf

Martinez Jr., C. R. (2006). Effects of differential family acculturation on Latino adolescent substance use. Family Relations, 55, 306-317. doi:10.1111/j.1741-3729.2006.00404.x

Martinez Jr., C. R., \& Eddy, J. M. (2005). Effects of culturally adapted parent management training on Latino youth behavioral health outcomes. Journal of Consulting and Clinical Psychology, 73, 841-851. doi:10.1037/0022-006X.73.5.841

Martinez Jr., C. R., McClure, H. H., \& Eddy, J. M. (2009). Language brokering contexts and behavioral and emotional adjustment among Latino parents and adolescents. The Journal of Early Adolescence, 29, 71-98. doi: $10.1177 / 0272431608324477$

Martinez Jr., C. R., McClure, H. H., Eddy, J. M., Ruth, B., \& Hyers, M. J. (2012). Recruitment and retention among Latino immigrant families in Oregon in prevention research. Prevention Science, 13, 15-26. doi:10.1007/s11121-011-0239-0

McClure, H. H., Martinez Jr., C. R., Snodgrass, J. J., Eddy, J. M., Jiménez, R., Isiordia, L. E. et al. (2010a). Discrimination-related stress, blood pressure, and Epstein Barr Virus antibodies among Latin American immigrants in Oregon. Journal of Biosocial Science, 42, 433-461. doi:10.1017/S0021932010000039

McClure, H. H., Snodgrass, J. J., Martinez Jr., C. R., Eddy, J. M., Jiménez, R. A., \& Isiordia, L. E. (2010b). Discrimination, psychosocial stress, and health among Latin American immigrants in Oregon. American Journal of Human Biology, 22, 421-423. doi:10.1002/ajhb.21002

McClure, H. H., Snodgrass, J. J., Martinez Jr., C. R., Eddy, J. M., Midttveit, E. C., \& Jiménez, R. A. (2010c). Psychosocial stress exposure and salivary cortisol among Latino immigrants in Oregon. Denver, CO: Society for Prevention Research Annual Conference.

McClure, H. H., Snodgrass, J. J., Martinez Jr., C. R., Squires, E. C., Jiménez, R. A., Isiordia, L. E. et al. (2012). Stress, place, and allostatic load among Mexican immigrant farmworkers in Oregon. Journal of Immigrant and Minority Health, Submitted.

McDade, T. W. (2007). Measuring immune function: Markers of cellmediated immunity and inflammation in dried blood spots. In G. H. Ice, \& G. D. James (Eds.), Measuring stress in humans: A practical guide for the field. Cambridge: University Press.

McDade, T. W., Burhop, J., \& Dohnal, J. (2004). High sensitivity enzyme immunoassay for C-reactive protein in dried blood spots. Clinical Chemistry, 50, 652-654. doi:10.1373/clinchem.2003.029488

McDade, T. W., Stallings, J. F., Angold, A., Costello, E. J., Burleson, M., Cacioppo, J. T., et al. (2000). Epstein-Barr Virus antibodies in whole blood spots: A minimally invasive method for assessing an aspect of cell-mediated immunity. Psychosomatic Medicine, 62, 560567.

McDade, T. W., Williams, S., \& Snodgrass, J. J. (2007). What a drop can do: Dried blood spots as a minimally invasive method for integrating biomarkers into population-based research. Demography, 44, 899-925. doi:10.1353/dem.2007.0038

McEwen, B. S. (2000). Allostasis and allostatic load: Implications for neuropsychopharmacology. Neuropsychopharmacology, 22, 108-124. doi:10.1016/S0893-133X(99)00129-3

McEwen, B. S., \& Wingfield, J. (2003). The concept of allostatis in biology and biomedicine. Hormones and Behavior, 43, 2-15. doi:10.1016/S0018-506X(02)00024-7 
Midttveit, E. C., McClure, H. H., Snodgrass, J. J., McDade, T. W., Martinez Jr., C. R., Eddy, J. M. et al. (2010). Body composition and lifestyle correlates of high sensitivity C-reactive protein among Latino immigrants in Oregon. American Journal of Human Biology, 22, 263.

National Institutes of Health (NIH) (2001). NIH policy and guidelines on the inclusion of women and minorities as subjects in clinical research.

http://grants.nih.gov/grants/funding/women_min/guidelines_amende d 10 2001.htm

National Institutes of Health (NIH) (2002). Outreach notebook for the inclusion, recruitment and retention of women and minority subjects in clinical research. URL (last checked 12 May 2009).

http://orwh.od.nih.gov/pubs/outreach.pdf

Nazmi, A., \& Victora, C. G. (2007). Socioeconomic and racial/ethnic differentials of C-reactive protein levels: A systematic review of population-based studies. BMC Public Health, 7, 212. doi:10.1186/1471-2458-7-212

Pepys, M. B., \& Hirschfeld, M. (2003). C-reactive protein: A critical update. Journal of Clinical Investigation, 111, 1805-1812. doi:10.1172/JCI18921

Pollard, T. M., \& Ice, G. H. (2007). Measuring hormonal variation in the hypothalamic pituitary adrenal axis: Cortisol. In G. H. Ice, \& G. D. James (Eds.), Measuring stress in humans: A practical guide for the field. Cambridge: University Press.

Rexrode, K. M., Pradhan, A., Manson, J. E., Buring, J. E., \& Ridker, P. M. (2003). Relationship of total and abdominal adiposity with CRP and IL-6 in women. Annals of Epidemiology, 13, 674-682. doi:10.1016/S1047-2797(03)00053-X

Ridker, P. M., Buring, J. E., Shih, J., Matias, M., \& Hennekens, C. H. (1998). Prospective study of C-reactive protein and the risk of future cardiovascular events among apparently healthy women. Circulation, 98, 731-733. doi:10.1161/01.CIR.98.8.731

Rumbaut, R. G., \& Portes, A. (2001). Ethnicities: Children of immigrants in America. New York: Sage.

Ryan, A. M., Gee, G. C., \& Laflamme, D. F. (2006). The association between self-reported discrimination, physical health and blood pressure: Findings from African Americans, Black immigrants, and Latino immigrants in New Hampshire. Journal of Health Care for the Poor and Underserved, 17, 116-132. doi:10.1353/hpu.2006.0092

Sapolsky, R. M., Romero, L. M., \& Munck, A. U. (2000). How do glucocorticoids influence stress responses? Integrating permissive, suppressive, stimulatory, and preparative actions. Endocrine Reviews, 21, 55-89. doi:10.1210/er.21.1.55

Sattar, N., McConnachie, A., Shaper, A. G., Blauw, G. J., Buckley, B. M., de Craen, A. J. et al. (2008). Can metabolic syndrome usefully predict cardiovascular disease and diabetes? Outcome data from two prospective studies. Lancet, 371, 1927-1935.

doi:10.1016/S0140-6736(08)60602-9

Selye, H. (1956). The stress of life. New York: McGraw-Hill.

Smokowski, P. R., \& Bacallao, M. L. (2007). Acculturation, internalizing mental health symptoms, and self-esteem: Cultural experiences of Latino adolescents in North Carolina. Child Psychiatry and $\mathrm{Hu}$ man Development, 37, 273-292. doi:10.1007/s10578-006-0035-4

Squires, E. C., McClure, H. H., Martinez Jr., C. R., Eddy, J. M., Jimenez, R. A., Isiordia, L. E. et al. (2012). Diurnal cortisol rhythms among Latino immigrants in Oregon. Journal of Physiological Anthropology, 31, 19. doi:10.1186/1880-6805-31-19

Steffen, P. R., Smith, T. B., Larson, M., \& Butler, L. (2006). Acculturation to Western Society as a risk factor for high blood pressure: A meta-analytic review. Psychosomatic Medicine, 68, 386-397. doi:10.1097/01.psy.0000221255.48190.32

The Urban Institute (2010). Children of immigrants data tool. Minnesota Population Center Integrated Public Use Microdata Series. http://datatool.urban.org/charts/datatool/pages.cfm

US Census Bureau (2011). 2011 Population estimates. http://www.census.gov/popest/data/national/asrh/2011/index.html

Vega, W. A., \& Kolody, B. (1985). The meaning of social support and the mediation of stress across cultures. In W. A. Vega, \& M. R. Miranda (Eds.), Stress and Hispanic mental health: Relating research to science delivery (pp. 48-75). Rockville, MD: National Institute of Mental Health.

Vega, W. A., Sribney, W., Aguilar-Gaxiola, S., \& Kolody, B. (2004). 12-month prevalence of DSM-II-R psychiatric disorders among Mexican Americans: Nativity, social assimilation, and age determinants. The Journal of Nervous and Mental Disease, 192, 532-541. doi:10.1097/01.nmd.0000135477.57357.b2

Villarruel, A. M., Jemmott, L. S., Jemmott, J. B., \& Eakin, B. L. (2006). Recruitment and retention of Latino adolescents to a research study: Lessons learned from a randomized clinical trial. Journal for Specialists in Pediatric Nursing, 11, 244-250. doi:10.1111/j.1744-6155.2006.00076.x

Vitaliano, P. P., Scanlan, J. M., Zhang, J., Savage, M. V., Hirsch, I. B., \& Siegler, I. C. (2002). A path model of chronic stress, the Metabolic Syndrome, and coronary heart disease. Psychosomatic Medicine, 64, 418-435.

Weigensberg, M. J., Toledo-Corral, C. M., \& Goran, M. I. (2008). Association between the Metabolic Syndrome and serum cortisol in overweight Latino youth. Journal of Clinical Endocrinology \& Metabolism, 93, 1372-1378. doi:10.1210/jc.2007-2309

Williams, D. R., Neighbors, H. W., \& Jackson, J. S. (2003). Racial/ ethnic discrimination and health: Findings from community studies. American Journal of Public Health, 93, 200-208. doi:10.2105/AJPH.93.2.200 